SUMMARY

The permanganate method for the determination of iodine in the presence of bromides and chlorides gives very satisfactory results.

Distillation with potassium bichromate will not completely liberate iodine from iodides.

Iodide in the presence of as much as ro g. sodium chloride can be determined with satisfactory results by distilling with ferric sulfate.

Iodide can be determined quite accurately in the presence of bromide by a single distillation with ferric sulfate if the quantity of bromide present in the sample does not greatly exceed $0.4 \mathrm{~g}$. This method is especially recommended for removing iodine from the sample which is to be used for the bromine determination.

Iodine may be determined in the presence of large amounts of bromide by making a double distillation with ferric sulfate. However, this method is more tedious and time-consuming than the permanganate method and the results obtained not quite so accurate.

Bureau of Chemistry

DEPARTMENT OF AGRICULTURE

WASHINOTON, D. C.

\section{STUDIES ON CANNING}

\section{AN APPARATUS FOR MEASURING THE RATE OF HEAT PENETRATION}

By W. T. Bovie AND J. BroNFENBRENNER

Received December 17, 1918

The changes in the rate of destruction of bacteria at various temperatures is no exception to the general rule that the speed of reactions greatly increases with temperature. For example, according to Miss $\mathrm{H}$. Chick, the temperature coefficient, ${ }^{2} \mu$, for the killing of Bacillus typhosus in hot water is $92,000,{ }^{3}$ and for the destruction of the Bacillus paratyphosus by means of phenol $\mu=48,000$. For comparison, the value $\mu$ for the hydrolysis of cane sugar by acid is given by Arrhenius as 25,600.

Since the rate of sterilization is inversely proportional to the time necessary for killing, we have, in any problem of sterilization by heat, at least two variables-time and temperature. In the case of sterilization of canned foods by heat a third variable, namely, the distance of any particular organism from the surface of the can, must be considered. It is impossible from the data now at hand to formulate a law connecting these three variables-time, space, and temperature-for, due to the heterogeneous nature of most canned goods and the possible changes in the physical properties as sterilization proceeds, there is an ever varying amount of heat transferred by con-

1 This work is a part of the investigation of food poisoning, conducted under the direction of Dr. M. J. Rosenau, Professor of Preventive Medicine and Hygiene, Harvard Medical School. The investigations were done under the auspices of the Advisory Committee of the National Research Council on the Toxicity of Preserved Foods, and under a grant to Harvard University from the National Canners' Association.

2 The relation between the rates of destruction $K_{0}$ and $K_{1}$ for two different temperatures $T_{0}$ and $T_{1}$, respectively, is given by the formula

$$
K_{1}=K_{0 E} \frac{\mu}{2}\left(\frac{T_{1}-T_{0}}{T_{0} T_{1}}\right),
$$

in which $\epsilon$ is the base of the natural system of logarithms, and $\mu$ is a constant which is greater the more rapid the rate of destruction.

- Calculated from the data given by Miss H. Chick, "The Process of Disinfection by Chemical Agencies and Hot Water," J. Hyg., 10 (1910), 237.

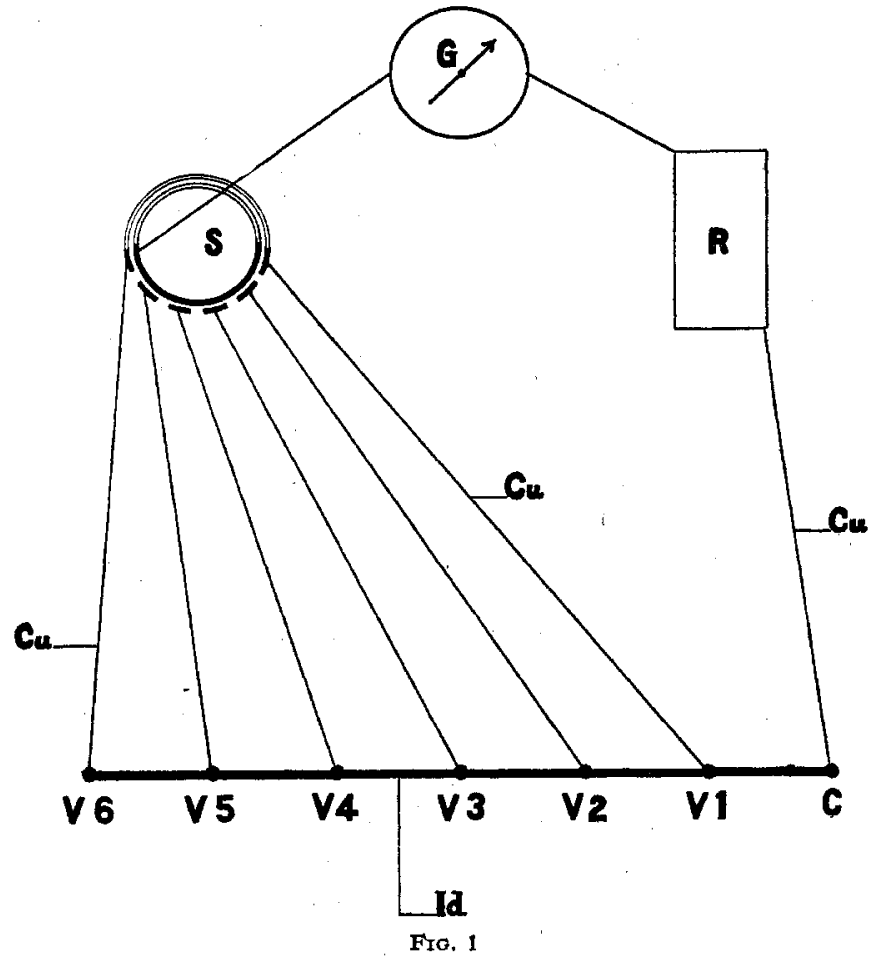

vection from the outside of the can towards the center. A mathematical treatment of the problem such as might be given for the transfer of heat in a solid conductor, as a disc of iron, is quite out of the question. ${ }^{1}$

In the present paper a method is described for determining experimentally the rate of heat transfer in canned foods, during the process of sterilization. The apparatus to be described below has passed through

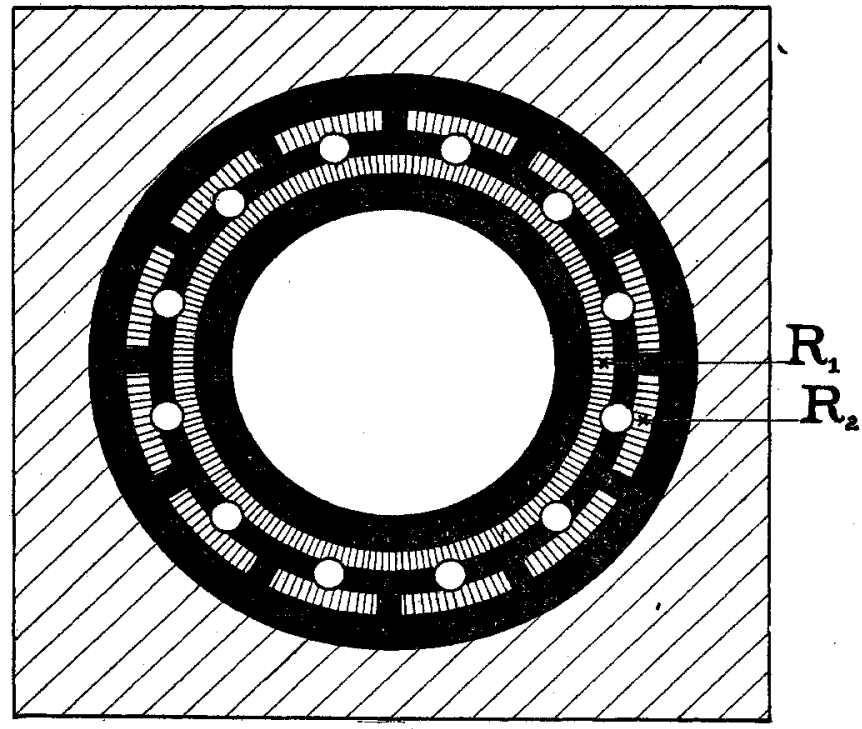

Fig. 2

I R. E. Buchanan gives a formula which contains the diffusivity of the canned food as a constant term. Experiments which will be reported later show that, especially with starchy foods, the diffusivity changes during the process of cooking. The change is undoubtedly caused by the absorption of water by the various components of the food. Since the amount of this absorption is influenced by the ripeness of the food, the acidity, etc., the possibility of a practical application of Buchanan's formula seems very doubtful. (R. E. Buchanan, et al., "Notes on Conditions which Influence Thermal Death Points," Abstr. of Bact., 2 (1918), 5.) 
various stages of improvement until a form yielding quite satisfactory results has been obtained. Our problem consists in finding the rate of transfer of heat from the outside towards the center of cans of food during the process of cooking and sterilization, as affected by the variations of the autoclave temperature, size of can, viscosity of the food, etc., such as are encountered by the commercial canner. It was necessary, therefore, to make the temperature measurements while the can was sealed and under pressure in the autoclave. Therefore, an electrical method of measuring the temperature was selected.

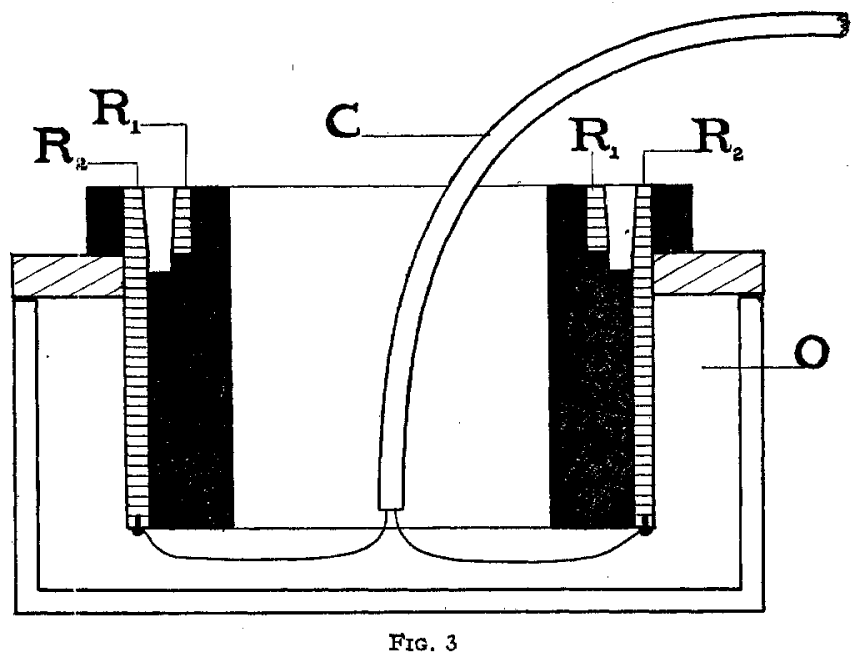

At first we considered adopting the apparatus which was used by Dr. Buchanan in the experiments referred to above and which Dr. G. E. Thompson was kind enough to describe to us in detail in private correspondence. This apparatus consists of a thermocouple, the constant junction of which is kept outside of the autoclave at a temperature of $0^{\circ} \mathrm{C}$., and the variable junction is led to the center of the can within the autoclave through a suitable steam-tight joint. It is evident that with this arrangement, the temperature variations of the autoclave must be recorded separately, and the final results corrected for these variations. Further, we thought that it would be incorvenient to maintain the temperature of the constant junction at $0^{\circ} \mathrm{C}$. in the vicinity of the autoclave.

It occurred to us that it might be advantageous to follow the rate and course of the convection currents upon which, at least in certain kinds of products, the rate of heat penetration largely depends. Therefore, in addition to the variable thermojunction at the center, we placed other junctions at several points within the can.

Our present apparatus consists of a constant thermojunction which is maintained at the temperature of the autoclave and is located just outside of the can. The actual temperature of this junction is obtained from the readings of a thermograph, the bulb of which is placed close to the constant junction. The capillary tube connecting the thermograph bulb with the recording clock is led out of the autoclave through a suitable steam-tight joint.
Connected with the constant junction is a series of variable junctions located in various parts of the can. The thermocouples are connected through a cable of wires to a galvanometer outside of the autoclave. From the deflections of the galvanometer, differences in temperature between that of the autoclave at the constant junction and any particular variable junction within the can could be determined. Temperature measurements could be made at any time during the process of heating and subsequent cooling.

Since measurements closer than $\mathrm{I}^{\circ} \mathrm{C}$. were not called for, such refinements as high insulation and shields for protection against stray currents were dispensed with. The deflections of the galvanometer caused by the thermoelectric currents were noted and converted into degrees of temperature difference between the junctions. The factor for this conversion was established by a large series of experiments in which the temperatures at different junctions were measured by mercury thermometers. (With the particular galvanometer used, r.8 units of deflection corresponded to $\mathrm{I}^{\circ} \mathrm{C}$. difference in temperature, or, as it happened, I unit of deflection corresponded to $I^{\circ} \mathrm{F}$.)

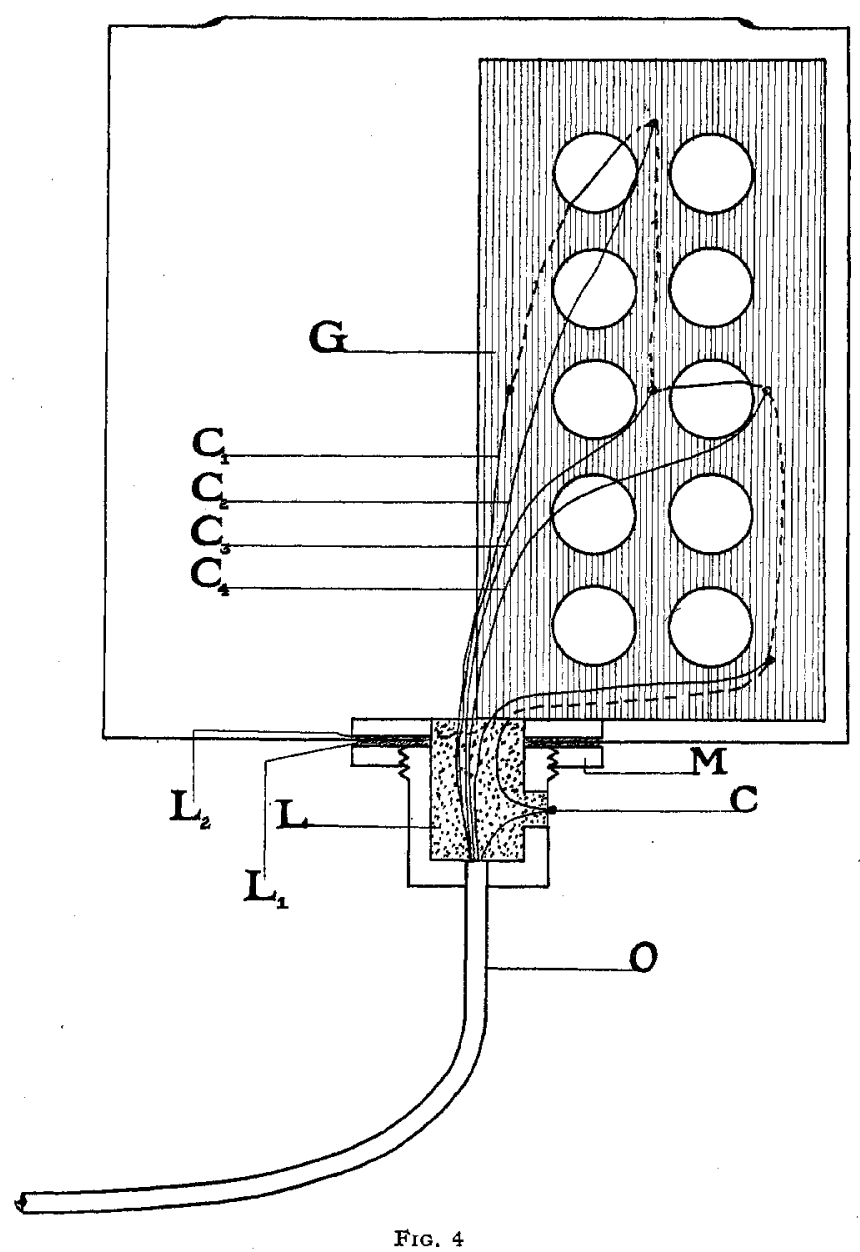

A wiring diagram of the thermocouple is shown in Fig. $x$. The couple was formed from No. 30 copper and ideal wires, marked $\mathrm{Cu}$ and $\mathrm{Id}$ in the diagram. $\mathrm{G}$ is the galvanometer, $\mathrm{C}$ the constant junction, $\mathrm{V}_{\mathbf{l}}$, 
$V_{2}, \quad V_{6}$ the variable junctions. $R$ is a variable resistance for cutting down the current when the difference in temperature between two junctions was so great as to cause deflections beyond the galvanometer scale. $S$ is a circular twelve-point changing switch for connecting the galvanometer with the variable junctions $V_{1}, V_{2}, V_{6}$.

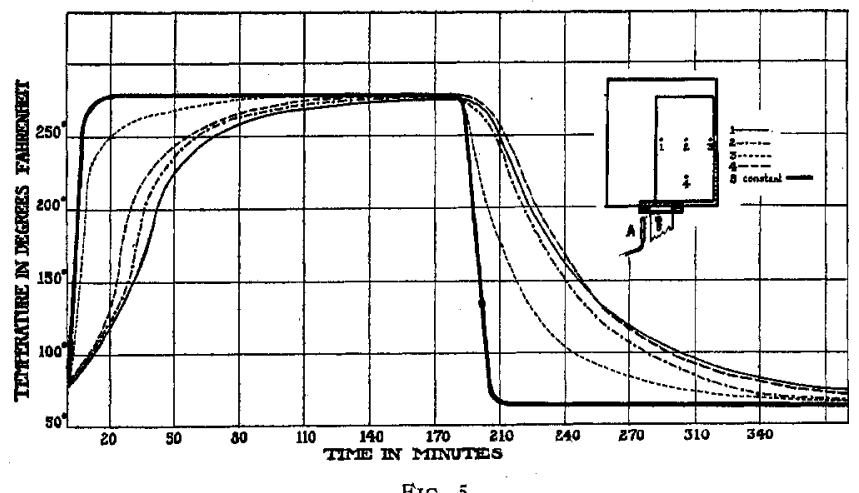

Frg. 5

A detail of this changing switch is shown in Figs. 2 and 3. Fig. 2 is from above; Fig. 3 is a vertical section. The solid black portions are formed of bakelite. $R_{1}$ and $R_{2}$ are of copper. The leads from the variable junctions are connected at the bottom of the outer ring of contacts. A copper wire connects the galvanometer with the inner ring. A copper pin inserted in any one of the holes connects the outer contact with the inner ring, thus completing the circuit through the particular junction connected with this contact. In order to avoid thermoelectric currents, the pins, contacts, and both rings, $R_{1}$ and $R_{2}$, were all formed from the same piece of copper tubing. As a further precaution, the bakelite support and the copper rings were suspended in a constant temperature oilbath, $O$. (With the degree of accuracy demanded by these experiments this precaution was later found to be unnecessary.) $\mathrm{C}$ is a lead conduit through which the cable of wires from the thermocouples passes to the switch.

Fig. 4 shows the construction of the grid which supports the variable junctions. The grid is placed in the can through the opening before the cover is sealed at the top, the lead cable $O$ being passed down through a round hole which has been cut in the bottom of the can. By means of the litharge packing $L$, the leather washers $L_{1}$ and $L_{2}$, and the nut $M$, a steam-tight joint is made at the bottom of the can. The constant junction is at $C$. The grid $G$ is made of lignum-vitae. The ideal wire passes from the constant junction $\mathrm{C}$, through the litharge packing and along the back of the grid $G$, as shown by the dotted line. The copper wires $\mathrm{C}_{1}, \mathrm{C}_{2}, \mathrm{C}_{3}$, etc., pass through holes in the grid and form the variable junctions where they are soldered to the ideal wire. The leads from the constant junction and from the variable junctions pass through the lead cable $O$ and out through the side of the autoclave. The copper leads are insulated with asbestos covering. The entire cable of copper wires is further wound with a single layer of asbestos cord.

As an example of the results obtained with this apparatus, we reproduce a graph, Fig. 5, showing a set of readings from a can of navy beans. On this graph the heavy line is a reproduction of the tracing of the thermograph record of the autoclave temperature. The abscissae and ordinate scales represent respectively the time in minutes and the temperature in degrees Fahrenheit. The other curves on the graph represent readings from the various thermojunctions. The drawing in the upper right-hand corner is a schematic illustration showing the location of the respective thermojunctions.

The temperature of the constant junction (No. 5 in the illustration) is measured by the bulb of the thermograph, A, and is represented graphically by the heavy curve. In the experiment which this graph represents, the can was placed in the autoclave and steam was turned on. As will be seen, a constant autoclave temperature of $280^{\circ} \mathrm{F}$. was reached in I 5 min. The can remained at this temperature for I 80 min., and then the pressure of the autoclave was released, the autoclave opened, and both the can and the bulb of the thermograph quickly immersed in water.

Department OF PREVENTIVE MEDTCINE AND Hygiene Harvard MEdical Schoor, Boston, MassachusetTs

\section{LABORATORY AND PLANT}

\section{COMPARATIVE TESTS OF PALAU AND RHOTANIUM WARE AS SUBSTITUTES FOR PLATINUM LABORATORY UTENSILS ${ }^{1}$}

By I. J. GUREVICH AND E. WICHers

Received February 14, 1919

The high cost and scarcity of platinum have greatly stimulated, especially within the past few months, the production of "platinum substitutes" for various purposes. Of those intended for use as chemical laboratory ware, no alloy of base metals tested by the Bureau of Standards has been found suitable. Two types of alloys of gold and palladium have been placed on the market and have come into more or less general

Published by permission of the Director of the Bureau of Standards. use. These are known as "palau" and "rhotanium." Rhotanium ware is manufactured in several grades, with varying proportions of gold and palladium. A discussion of these alloys, together with tests made by Professor H. H. Willard, has been published by Dr. F. A. Fahrenwald. ${ }^{1}$

A series of tests has been carried out at this Bureau to determine the suitability of these alloys as substitutes for platinum in laboratory ware. Four rhotanium crucibles, two of grade $A$ and two of grade $C$, were submitted for test purposes by Dr. Fahrenwald. This Bureau had previously carried out tests on a palau crucible submitted by the Pacific Platinum Works,

1 This Journal, 9 (1917), 590. 